\title{
Study of phenolic compounds and lipids of grape pomace
}

\author{
Natalia Ageyeva*, Anastasia Tikhonova, Svetlana Biryukova, and Ekaterina Globa \\ North-Caucasian Federal Scientific Center of Horticulture, Viticulture, Winemaking, Im. 40-letiya \\ Pobedy Str. 39, Krasnodar, 350901, Russian Federation
}

\begin{abstract}
The article is devoted to the research of the makeup of phenolic compounds and fatty acids of grape pomace. The phenolic compounds were identified in skin and seed extracts and in extracts of skin-and-seed mixtures; the fatty acids - in grape oil generated by direct pressing. It was established that anthocyanins were present mainly in the skins. Low concentrations of ten components of the anthocyanin complex were identified in the Saperavi seeds. Maximum amounts of anthocyanins were found in the Saperavi skins. The concentration of quercetin distinguished by a PP-vitamin activity was by 1.5 to 2.0 times higher in the skin-andseed mixtures, especially of Roesler grapes, than in the skin itself. Maximum amounts of flavan-3-ols, hydroxy-cinnamic and hydroxybenzoic acids and oligomeric procyanidins, as well as the highest antioxidant activity were observed in the skin-and-seed mixture. The highest value of the correlation factor was observed in cases of interaction of antioxidant activity and concentration of procyanidins $(r=0.83)$, antioxidant activity and concentration of anthocyanins $(\mathrm{r}=0.78)$, and antioxidant activity and concentration of flavan-3-ols $(r=0.75)$. Among the flavan-3-ols, it was (+)-D-Catechin that prevailed in grape seeds, with its concentration in the Pinot Noir extract (OAO APF Fanagoria) reaching $468 \mathrm{mg} / \mathrm{dm}^{3}$. Maximum concentration of Epigallocatechin-gallate was observed in the Saperavi and Pinot Noir seeds. As regards the concentration of hydroxy-cinnamic acids in the seeds, n-coumaric acid (Ancellotta, Saperavi) stood apart among the others; gallic acid (Saperavi, Ancellotta) came forward among the hydroxy-benzoic acids. In the reviewed samples of grape seeds, procyanidins of groups $B_{1}, B_{2}$ and $B_{3}$ distinguished by high antioxidant activity prevailed. Prevalence of linoleic and oleic acids was established for grape oil extracted from the seeds of such red grape varieties as Cabernet Sauvignon, Pinot Noir and Saperavi. Maximum concentrations of oleic acid were found in the Pinot Noir and Riesling seeds. Palmitic and stearic acids were also available in rather high concentrations in the grape oil.
\end{abstract}

\footnotetext{
*Corresponding author: ageyeva@inbox.ru
} 


\section{Introduction}

Grape pomace (marc) obtained in the process of industrial processing of grapes at primary wineries by crushing fresh or fermented must, is considered as winemaking waste. Its quantity varies between 17 and $22 \%$, depending upon the grape variety and the processing technology (averagely, 10 to $15 \mathrm{~kg} / 100 \mathrm{~kg}$ of processed grapes). The mechanical makeup of pomace is represented by grape juice, skins, pulps, and seeds. The chemical composition of grape pomace of white and red varieties is variegated; it includes components of various nature - polyphenols, polysaccharides, nitrogenous matters, vitamins, major and minor nutrients; and lipids contained in seeds. Their sustainable use will make it possible to produce various food products, including with functional properties $[1,2,3,4,5]$, and antiradical and antioxidant activity $[6,7,8,9,10]$ - viz., polyphenol concentrates, grape oil, soft drinks, dietary fibres, etc. [11, 12, 13, 14, 15]. Because of that, acquisition of new knowledge is required about grape pomaces with maximum amounts of the listed biologically valuable components in order to develop the technologies for concrete new kinds of products with due account given to their localization in different elements of the pomace.

The purpose of this work was to gain new knowledge on the chemical composition of phenolic compounds and lipids in grape pomace.

\section{Study objects and methods}

As the study objects, the following dried substances were used:

- skins of red grape varieties derived from different Krasnodar wineries: Merlot (JSC Divnomorye), Cabernet Sauvignon (CJSC Slavprom), and Roesler (OAO APF Fanagoria); - seeds of Pinot Noir (APF Fanagoria); Syrah, Merlot and Ancellotta (all from JSC Divnomorye); Pinot Noir, Merlot, Saperavi and Cabernet Sauvignon (all from LLC Olimp).

The phenolic compounds were extracted from the pomace and seeds at the temperature of $20-24^{\circ}$ for 5 months by an aqueous alcoholic solution with $70 \%$ alcohol by volume. The mass concentration of the phenolic compounds was determined by high-performance chromatography method with the use of the Agilent Technologies (model 1100) chromatographic system with a diode matrix detector. For separation purposes, we used a $2.1 \times 150$ mm Zorbax SB-18 chromatographic column, filled with silica gel with bonded octadecylsilyl phase with $3.5 \mu \mathrm{m}$ sorbent particles. The elution was performed in gradient mode. The eluent flow rate was $0.25 \mathrm{ml} / \mathrm{min}$. To build the gradient, the following were used: solution A - methanol; solution B - an $0.6 \%$ aqueous solution of trifluoroacetic acid. The volume of the input sample was $2 \mu \mathrm{l}$. The chromatograms were registered by optical absorption of the eluate at the following wave lengths: $280 \mathrm{~nm}$ for gallic acid, (+)-DCatechin, (-)-Epicatechin, and procyanidins; $313 \mathrm{~nm}$ for derivative hydroxy-cinnamic acids; $371 \mathrm{~nm}$ for quercetin; $350 \mathrm{~nm}$ for glycosides of quercetin; and $525 \mathrm{~nm}$ for anthocyanins. To register trans-resveratrol, a fluorometric detector was used at absorption wavelength of 280 $\mathrm{nm}$ and emission wavelength of $320 \mathrm{~nm}$. The components were identified by comparison of the spectral performances and peak retention times in the reviewed samples and in standard calibration solutions. The quantitative contents of individual components were calculated with the use of calibration curves of dependance of peak responses upon substance concentrations drawn by solutions of individual substances. The value of antioxidant activity expressed in terms of TROLOX (6-hydroxy-2,5,7,8-tetramethylchromane-2carbonic acid - a synthesized analogue of gallic acid) was performed on the "ColourYauza-01-AA" chromatograph [16]. The statistical data processing was performed with the use of Microsoft Excel software. 
The grape oil was generated from ground grape seeds by direct pressing according to [17] method. The fatty and acid composition was identified by gas-liquid chromatography at the Crystal-2000M chromatograph. A 30-metre-long spiral stainless-steel gas chromatographic column was used. Pro analysis compressed nitrogen was used as the carrying gas. A sample of the analyzed product was injected into the chromatographic column with a microsyringe through the evaporator by piercing the rubber membrane. The components were identified by the retention time.

\section{Results and discussion}

Table 1 presents the results of the study of phenolic compounds in the skins and skin-andseed mixture.

Table 1. Compositional makeup of polyphenolic compounds in aqueous alcoholic extracts of grape skin and skin-and-seed mixture.

\begin{tabular}{|c|c|c|c|c|c|c|}
\hline \multirow[b]{3}{*}{ Polyphenols } & \multicolumn{6}{|c|}{ Mass concentration of polyphenols in extracts, $\mathrm{mg} / \mathrm{dm}^{3}$} \\
\hline & \multicolumn{4}{|c|}{ Skins } & \multicolumn{2}{|c|}{ Seeds + skins } \\
\hline & 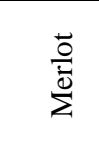 & 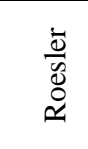 & 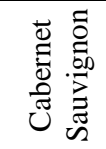 & 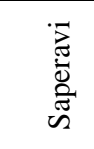 & 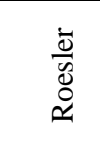 & 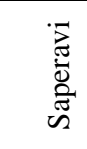 \\
\hline \multicolumn{7}{|c|}{ Anthocyanins } \\
\hline Delphinidin-3-O-glycoside & 23.5 & 22.7 & 27.8 & 36.2 & 22.0 & 37.1 \\
\hline Cyanidin-3-O-glycoside & 10.6 & 8.8 & 13.3 & 14.8 & 8.6 & 15.0 \\
\hline Peonidin-3-O-glycoside & 12.4 & 10.6 & 12.8 & 14.0 & 12.2 & 15.0 \\
\hline Petunidin-3-O-glycoside & 1.2 & 1.6 & 2.4 & 3.7 & 2.0 & 3.5 \\
\hline Malvidin-3-O-glycoside & 156 & 154 & 166 & 178 & 157 & 178 \\
\hline Delphinidin-3-O-(6'-acetyl-glycoside) & 16.5 & 15.4 & 18.7 & 21.7 & 15.2 & 22.4 \\
\hline Cyanidin-3-O-(6'-acetyl-glycoside) & 1.2 & 1.2 & 2.0 & 2.5 & 1.2 & 2.5 \\
\hline Peonidin-3-O-(6'-acetyl-glycoside) & 3.4 & 4.0 & 5.2 & 5.4 & 4.3 & 5.0 \\
\hline Petunidin-3-O-(6'-acetyl-glycoside) & 1.7 & 1.5 & 2.1 & 2.2 & 2.2 & 2.3 \\
\hline Malvidin-3-O-(6'-acetyl-glycoside) & 2.0 & 1.9 & 2.5 & 2.7 & 2.4 & 3.0 \\
\hline $\begin{array}{l}\text { Delphinidin-3-O-(6'-n-coumaroyl- } \\
\text { glycoside) }\end{array}$ & 2.1 & 1.7 & 3.1 & 4.8 & 3.1 & 5.0 \\
\hline Petunidin-3-O-(6'-n-coumaroyl-glycoside) & 0.7 & N/A & 1.1 & N/A & 2.1 & N/A \\
\hline Malvidin -3-O-(6'-n-coumaroyl-glycoside) & 2.3 & 3.6 & 2.8 & 2.7 & 4.3 & 3.0 \\
\hline Total anthocyanins & 233.6 & 227.0 & 259.8 & 288.7 & 236.6 & 291.8 \\
\hline \multicolumn{7}{|c|}{ Flavones } \\
\hline Quercetin & 42.8 & 43.7 & 46.5 & 51.5 & 88.0 & 52.0 \\
\hline \multicolumn{7}{|c|}{ Flavan-3-ols } \\
\hline$(+)$-D-Catechin & 332 & 345 & 374 & 412 & 867 & 940 \\
\hline (-)-Epicatechin & 138 & 147 & 154 & 166 & 450 & 564 \\
\hline
\end{tabular}




\begin{tabular}{|c|c|c|c|c|c|c|}
\hline \multirow[b]{3}{*}{ Polyphenols } & \multicolumn{6}{|c|}{ Mass concentration of polyphenols in extracts, $\mathrm{mg} / \mathrm{dm}^{3}$} \\
\hline & \multicolumn{4}{|c|}{ Skins } & \multicolumn{2}{|c|}{ Seeds + skins } \\
\hline & 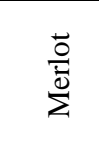 & 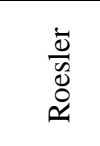 & 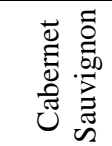 & 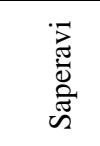 & 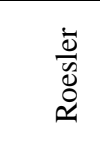 & 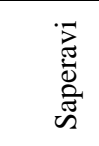 \\
\hline (-)-Epicatechin-gallate & 0.5 & 1.3 & 0.7 & 2.4 & 15.2 & 47.0 \\
\hline Total flavan-3-ols & 470.5 & 493.3 & 528.7 & 580.4 & 1332.2 & 1551.0 \\
\hline \multicolumn{7}{|c|}{ Hydroxy-cinnamic acids } \\
\hline Caftaric acid & 420 & 440 & 480 & 486 & 522 & 497 \\
\hline Cautaric acid & 13.4 & 15.5 & 14.6 & 17.2 & 37.0 & 18.0 \\
\hline n-Coumaric acid & 2.6 & 2.0 & 2.2 & 2.5 & 15.3 & 125 \\
\hline Total hydroxy-cinnamic acids & 436.0 & 457.5 & 496.8 & 660.5 & 574.3 & 640.0 \\
\hline \multicolumn{7}{|c|}{ Hydroxy-benzoic acids } \\
\hline Gallic acid & 47.4 & 62.1 & 58.3 & 87.0 & 425 & 278 \\
\hline Syringic acid & 34.3 & 45.6 & 51.4 & 64.2 & 282 & 179 \\
\hline Total hydroxy-benzoic acids & 81.7 & 107.7 & 109.7 & 151.2 & 707 & 457 \\
\hline \multicolumn{7}{|c|}{ Oligomeric procyanidins } \\
\hline Procyanidin B1 & 17.0 & 14.2 & 18.4 & 21.0 & 246 & 358 \\
\hline Procyanidin B2 & 1.2 & 2.3 & 3.0 & 4.2 & 158 & 230 \\
\hline Procyanidin B3 & 13.5 & 10.7 & 15.4 & 18.4 & 102 & 131 \\
\hline Procyanidin B5 & 2.2 & 2.6 & 3.0 & 3.0 & 35.3 & 56.1 \\
\hline Procyanidin B7 & 15.7 & 16.2 & 18.4 & 24.6 & 49.5 & 83.1 \\
\hline Total oligomeric procyanidins & 49.6 & 46.0 & 58.2 & 71.2 & 590.8 & 807.2 \\
\hline Total polyphenols & 1314.2 & 1275.2 & 1499.7 & 1803.5 & 3528.9 & 3779.0 \\
\hline $\begin{array}{l}\text { Antioxidant activity, } \mathrm{g} / \mathrm{dm}^{3} \text { in terms of } \\
\text { TROLOX }\end{array}$ & 18.3 & 18.8 & 19.6 & 21.4 & 30.4 & 37.6 \\
\hline
\end{tabular}

The performed studies showed that the concentration of anthocyanins, the main colouring agents of grape fruit, in the skin-and-seed mixture was practically identical to skin athocyanins, i.e. grape pomace anthocyanins are concentrated in the skins. Maximum quantity of anthocyanins was found in Saperavi skins. At the same time, it is worth noting the absence of petunidin-3-O-(6'-n-coumaroyl-glycoside) in Roesler which may have been explained by the genetic peculiarity of this grape variety.

The concentration of quercetin, a mighty antioxidant with a PP-vitamin activity, in the skin-and-seed mixture, especially of Roesler grapes, was by 1.5 to 2.0 times higher than in the skins, and varied depending on the study object.

Seeds made a valuable contribution to the aggregate accumulation of flavan-3-ols, hydroxy-cinnamic and hydroxy-benzoic acids, and in particular oligomeric procyanidins, whose maximum values were found in the skin-and-seed mixture. The availability of the above listed compounds was important for the formation of antioxidant activity: its maximum value was observed in the skin-and-seed mixture. 
With the help of correlative analysis module, the existence of a statistically relevant relation between the antioxidant activity and a component of the phenolic complex. It is worth noting that the maximum value of the correlation factor was observed in cases of interaction of antioxidant activity and concentration of procyanidins $(r=0.83)$, antioxidant activity and concentration of anthocyanins ( $\mathrm{r}=0.78$ ), and antioxidant activity and concentration of flavan-3-ols $(r=0.75)$.

In light of the obtained results, research of the compositional makeup of seeds of various grape varieties is of great importance. The performed studies (Table 2) showed nearly a total absence of anthocyanins in grape seeds. None of the samples let us identify petunidin-3-O-glycoside, malvidin-3-O-glycoside, malvidin-3-O-(6'-acetyl-glycoside), or delphinidin-3-O-(6'-n-coumaroyl-glycoside). Anthocyianins were detected in small quantities in the seed extracts of Ancellotta and Saperavi grapes, characterized by coloured juice.

Table 2. Monomeric and oligomeric polyphenols in aqueous-alcoholic extracts of grape seeds.

\begin{tabular}{|c|c|c|c|c|c|c|c|c|c|}
\hline \multirow[b]{3}{*}{ Polyphenols } & \multicolumn{9}{|c|}{ Mass concentration of polyphenols in seed extracts, $\mathrm{mg} / \mathrm{dm}^{3}$} \\
\hline & \multicolumn{4}{|c|}{ JSC Divnomorye } & \multirow{2}{*}{ 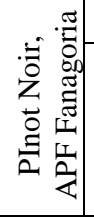 } & \multicolumn{4}{|c|}{ LLC Olimp } \\
\hline & 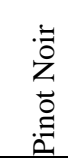 & 宽 & $\begin{array}{l}\frac{0}{0} \\
\sum^{\circ}\end{array}$ & 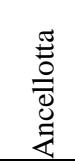 & & 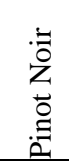 & 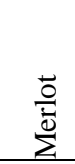 & 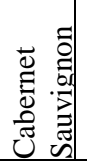 & 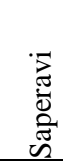 \\
\hline \multicolumn{10}{|c|}{ Anthocyanins } \\
\hline $\begin{array}{l}\text { Delphinidin-3-O- } \\
\text { glycoside }\end{array}$ & - & - & - & 0.2 & - & - & - & - & 0.4 \\
\hline Cyanidin-3-O-glycoside & - & - & - & - & - & - & - & - & 0.2 \\
\hline Peonidin-3-O-glycoside & - & - & - & - & - & - & - & - & 0.2 \\
\hline $\begin{array}{l}\text { Delphinidin-3-O-(6'-acetyl- } \\
\text { glycoside) }\end{array}$ & - & - & - & 0.6 & - & - & - & - & 1.0 \\
\hline Cyanidin-3-O-(6'-acetyl-glycoside) & - & - & - & - & - & - & - & - & 0.7 \\
\hline Peonidin-3-O-(6'-acetyl-glycoside) & - & - & - & 0.4 & - & - & - & - & 1.0 \\
\hline Petunidin-3-O-(6'-acetyl-glycoside) & - & - & - & - & - & - & - & - & 0.4 \\
\hline $\begin{array}{l}\text { Petunidin-3-O-(6'-n-coumaroyl- } \\
\text { glycoside) }\end{array}$ & - & - & - & - & - & - & - & - & 0.3 \\
\hline $\begin{array}{l}\text { Malvidin -3-O-(6'-n-coumaroyl- } \\
\text { glycoside) }\end{array}$ & - & - & - & 0.4 & - & - & - & - & 0.6 \\
\hline Total anthocyanins & - & - & - & 1.6 & - & - & - & - & 4.8 \\
\hline \multicolumn{10}{|c|}{ Flavones } \\
\hline Quercetin & 1.0 & - & - & 2.2 & - & 1.2 & - & 1.9 & 1.8 \\
\hline \multicolumn{10}{|c|}{ Flavan-3-ols } \\
\hline (+)-D-Cachetin & 452 & 413 & 347 & 386 & 468 & 457 & 361 & 432 & 448 \\
\hline (-)-Epicachetin & 391 & 312 & 334 & 377 & 388 & 376 & 341 & 392 & 312 \\
\hline (-)-Epicachetin-gallate & 53 & 31 & 33 & 43 & 54 & 57 & 34 & 50 & 55 \\
\hline \multicolumn{10}{|c|}{ Hydroxy-cinnamic acids } \\
\hline Caftaric acid & 0.8 & - & - & - & 1.2 & 1.4 & - & - & 0.8 \\
\hline
\end{tabular}




\begin{tabular}{|c|c|c|c|c|c|c|c|c|c|}
\hline \multirow[b]{3}{*}{ Polyphenols } & \multicolumn{9}{|c|}{ Mass concentration of polyphenols in seed extracts, $\mathrm{mg} / \mathrm{dm}^{3}$} \\
\hline & \multicolumn{4}{|c|}{ JSC Divnomorye } & \multirow{2}{*}{ 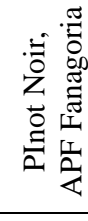 } & \multicolumn{4}{|c|}{ LLC Olimp } \\
\hline & $\begin{array}{l}:= \\
z \\
z \\
0 \\
0\end{array}$ & 胥 & $\frac{\overrightarrow{0}}{\stackrel{0}{c}}$ & 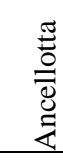 & & 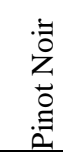 & $\frac{\overrightarrow{0}}{\sum^{\circ}}$ & 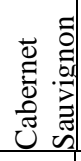 & 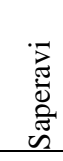 \\
\hline Cautaric acid & 0.3 & - & - & - & 0.5 & 0.5 & - & - & 0.4 \\
\hline n-Coumaric acid & 131 & 118 & 121 & 134 & 142 & 135 & 127 & 135 & 141 \\
\hline \multicolumn{10}{|c|}{ Hydroxy-benzoic acids } \\
\hline Gallic acid & 291 & 287 & 282 & 317 & 322 & 315 & 294 & 318 & 343 \\
\hline Syringic acid & 129 & 118 & 132 & 138 & 147 & 154 & 129 & 142 & 151 \\
\hline \multicolumn{10}{|c|}{ Oligomeric procyanidins } \\
\hline Procyanidin B1 & 341 & 310 & 287 & 326 & 334 & 337 & 318 & 322 & 337 \\
\hline Procyanidin B2 & 225 & 218 & 210 & 241 & 231 & 236 & 225 & 225 & 230 \\
\hline Procyanidin B3 & 114 & 100 & 100 & 112 & 116 & 117 & 98 & 100 & 121 \\
\hline Procyanidin B5 & 57 & 48 & 41 & 60 & 61 & 61 & 54 & 56 & 64 \\
\hline Procyanidin B7 & 68 & 54 & 60 & 58 & 66 & 70 & 57 & 65 & 70 \\
\hline
\end{tabular}

The presence of quercitin was identified in the seed extracts of Pinot Noir, Ancellotta (highest concentrations), Cabernet Sauvignon, and Saperavi.

According to contemporary views, cachetins are deemed as several derivatives varying in the stereoisomeric orientation of substituents with two chiral carbon atoms in the structure of a flavan-3-ol nucleus [18, 19]. There exist derivatives of catechin and gallocatechin; the latter can occur in the seeds of hybrid grape varieties. Out of the four possible stereoisomers, only two can occur in native form, viz.: (+)-D-catechin and (-)epicatechin. (-)-Epicatechin-gallate is a compound ester of (-)-epicatechin and gallic acid. One of the strongest natural antioxidants, (-)-epigallocatechin-gallate, is available in red wines and grape seeds.

Among the flavan-3-ols, (+)-D-Cachetin prevailed in grape seeds whose concentration in the Pinot Noir extract (Fanagoria) reached $468 \mathrm{mg} / \mathrm{dm}^{3}$. The maximum concentration of epigallocatechin-gallate was found in Saperavi and Pinot Noir seeds, which proved their high antioxidant characteristics.

Phenolic acids - hydroxy-cinnamic and hydroxy-benzoic ones - also reveal antioxidant properties. Gallic acid showed the highest activity [20, 21]. Among hydroxy-cinnamic acids, n-coumaric acid (Ancellotta, Saperavi) excelled by concentration; as for hydroxybenzoic acids, gallic acid (Saperavi, Ancellotta) stood out among the rest.

Polymeric procyanidins localized in seeds and partly in skins of grapes [22, 23] are deemed one of the most important and structurally diverse groups of polyphenols. In the analyzed grape seed samples, highly antioxidant procyanidins of $\mathrm{B}_{1}, \mathrm{~B}_{2}$ и $\mathrm{B}_{3}$ groups prevailed. Thus, it can be argued that grape seeds are a valuable source of antioxidants and a good primary material for the production of food products, including beverages with a high biological value. 
Table 3. Fatty and acid composition of grape oils.

\begin{tabular}{|c|c|c|c|c|c|c|c|}
\hline \multirow[b]{3}{*}{ Fatty acid } & \multicolumn{7}{|c|}{ Mass content of fatty acid, \% to total of fatty acids } \\
\hline & \multicolumn{7}{|c|}{ Grape variety } \\
\hline & 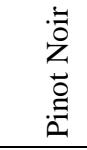 & $\begin{array}{l}\text { त्र } \\
\text { के }\end{array}$ & 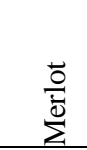 & 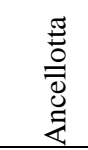 & 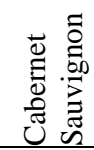 & 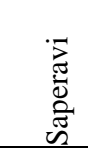 & 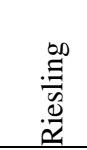 \\
\hline Myristic C14:0 & 0.14 & 0.10 & 0.11 & 0.04 & 0.11 & 0.13 & 0.10 \\
\hline Palmitinic C16:0 & 11.09 & 11.10 & 12.00 & 12.11 & 12.14 & 10.32 & 11.16 \\
\hline Palmitoleic C16:1 & 0.27 & 0.22 & 0.26 & 0.28 & 0.24 & 0.21 & 0.19 \\
\hline Stearic C18:0 & 9.54 & 7.72 & 8.36 & 7.64 & 11.12 & 10.54 & 5.72 \\
\hline Oleic C18:1 & 32.17 & 29.34 & 29.05 & 23.52 & 28.14 & 25.12 & 30.56 \\
\hline Linoleic C18:2 & 44.32 & 40.11 & 39.67 & 34.61 & 46.65 & 42.18 & 40.36 \\
\hline Linolenic C18:3 & 1.88 & 0.92 & 1.43 & 0.88 & 1.12 & 0.78 & 1.23 \\
\hline Arachic C20:4 & 0.38 & 0.23 & 0.41 & 0.19 & 0.32 & 0.32 & 0.28 \\
\hline Eicosenic C20:1 & 0.52 & 0.37 & 0.43 & 0.34 & 0.37 & 0.35 & 0.37 \\
\hline Behenic C21:0 & 0.48 & 0.37 & 0.37 & 0.14 & 0.22 & 0.27 & 0.26 \\
\hline Erucic C22:1 & 0.39 & N/A & 0.34 & $\mathrm{~N} / \mathrm{A}$ & N/A & 0.22 & 0.35 \\
\hline Lignoceric C23:0 & 0.88 & 0.62 & 9.56 & 0.32 & 0.56 & 0.63 & 0.67 \\
\hline
\end{tabular}

Grapevine is a heat-loving plant grown in open lowlands and hillsides that are well heated by sunlight and assimilate solar energy. Lipids are the main nutrients of grape seeds, which is why the plant's reaction to environmental conditions manifests itself as a change of the lipid complex. Grape seeds are distinguished by high oil content, and they are used as primary material for the production of grape oil [17, 24]. Besides, as it is noted by [25, 26, 27], the makeup of fatty acids of directly pressed grape oil considerably depends upon the grape variety. Our research has shown prevalence of linoleic and oleic acids in grape oil extracted from seeds of grapes of different varieties (Table 3). The highest concentration of linoleic acid was found in the oil extracted from seeds of the red grape varieties Cabernet Sauvignon, Pinot Noir and Saperavi, the most responsive to solar insolation. Pinot Noir and Riesling seeds were distinguished by the concentration of oleic acid. Palmitinic and stearic acids were also found in grape oil in rather high concentrations.

\section{Conclusion}

Thereby, the presented experimental data bear evidence to high biological value of grape seeds and necessity of development of contemporary processing technologies aimed at production of food products with functional properties.

\section{Funding}

The research was carried out with the financial support of the Kuban Science Foundation in the framework of the scientific project № МФИ-20.1/22 “Disclosure of the mechanisms of transformation of biological objects of secondary raw materials of the winemaking industry for targeted management of the processes of its storage and processing.”

\section{References}

1. P. Chowdhary, A.Gupta E. Gnansounou, A. Pandey, P. Chaturvedi, EP, 278, 116796 (2021) 
2. R. Sirohia, A.Tarafdar, S. Singh, T. Negi, V. K. Gaur, E. Gnansounou, B. Bharathiraja, BT, 314, 123771 (2020)

3. A.Tsali, A. M. Goula, PT, 340, 194-207 (2018)

4. G. Nakov, A. Brandolini, A. Hidalgo, N. Ivanova, V. Stamatovska, I. Dimov, LWT, 134, 109950 (2020)

5. C. G. Kato-Schwartz, R. C. G. Corrêa, D. S. Lima, A. B. Sá-Nakanishi, G. A. Gonçalves, F. A. V. Seixas, C. W. I. Haminiuk, L. Barros, I. C. F. R. Ferreira, A. Bracht, R. M. Peralta, FRI, 137, 109462 (2020)

6. I. M. Martins, G. A. Macedo, J. A. Macedo, FB, 35,100607 (2020)

7. G. C. Monteiro, I. O. Minatel, A. P. Junior, H. A. Gomez-Gomez, J. P. C. de Camargo, M. S. Diamante, L. S. P. Basílio, M. A. Tecchio, G. P. P. Lima, LWT, 135, 110053 (2021)

8. R. Harikrishnan, G. Devi, H.V. Doan, C. Balasundaram, M. Á. Esteban, M. AbdelTawwa, FSI, 111, 69-82 (2021)

9. C. Beres, S. P. Freitas, R. L.de O. Godoy, D. C. R. Oliveira, R. Deliza, M. Iacomini, C. Mellinger-Silva, L. M. C. Cabral, JFF, 56, 276-285 (2019)

10. M.-R. Meini, I. Cabezudo, C. E. Boschetti, D. Romanini, FCh, 283, 257-264 (2019)

11. Q. Jin, S. F. O’Keefe, A. C. Stewart, A. P. Neilson, Y. T. Kim, H. Huang, FBP, 127, 139-151 (2021)

12. N. S. Limareva, A. V. Mityanina, L. V. Donchenko, SNI, 4, 200-206 (2018)

13. A. V. Mityanina, Y. A. Andrzejchik, N. S. Limareva, EIQ manag, 1, $36-38$ (2018)

14. D. D. A. Kamer, T. Gumus, I. Palabiyik, A. S. Demirci, O. Oksuz, FH, 114, 106584 (2021)

15. A. N. Tikhonova, N. M. Ageeva, WW, 48, 52-53 (2019)

16. A. Y. Yashin, MI, 2, 13-16 (2008)

17. S. V. Tarasov, V. I. Martovshchuk, Y. A. Belyaeva, FT, 1, 6-9 (2015)

18. D. Del Rio, G. Borges, A. Crozier, Br. J. Nutr., 104, 67-90 (2010)

19. E. F. Gris, F. Mattivi, E. A. Ferreira, U. Vrhovsek, D. W. Filho, R. C. Pedrosa, M. T. Bordignon-Luiz, FCA, 31, 31-41 (2013)

20. S. Shabani, Z. Rabiei, H. Amini-Khoei, Intern. J. of FP, 23, 736-752 (2020)

21. M. Popov, A. Hejtmankova, Z. Kotikova, R. Stralkova, J. Lachman, Vitis, 56, 45-48 (2017)

22. A. Muñoz-Labrador, M. Prodanov, M Villamiel, US, 50, 74-81 (2019)

23. M. Trad, C. Le Bourvellec, H. B. Hamda, C. M. G. C. Renard, M. Harbi, E, 213, 242 (2017)

24. M. E. Martin, E. Grao-Cruces, M. C. Millan-Linares, S., Montserrat-De la Paz, F, 9, 1360 (2020).

25. F. B. Shinagawa, F. C. Santana, J. Mancini-Filho, Rev. Nutr., 28, 65-76 (2015)

26. F. B. Shinagawa, F. C. Santana, L. R. O. Torres, J. Mancini-Filho, FST, 35, 399-406 (2015)

27. D. B. Konuskan, O. Kamiloglu, O. Demirkeser, PER, 53, 144-150 (2019). 